\title{
US FARM BILL (2014) E DS522 (2016) X EFICIÊNCIA DAS DECISÕES DO OSC
}

\author{
Lara Bonemer Rocha Floriani" \\ Marcia Carla Pereira Ribeiro**
}

1 Introdução. 2 Eficiência na Análise Econômica do Direito. 3 Órgão de Solução de Controvérsias da Organização Mundial do Comércio. 4 DS46, DS70 e DS222 (Brasil e Canadá) e DS267 (Brasil e Estados Unidos da América). 4.1 DS 46 - Canadá x Brasil. 4.2 DS70 e DS 222 (Brasil x Canadá). 4.3 DS 267: Brasil x EUA. 5 US Farm Bill (2014) e DS522. 6 Conclusão. Referências.

\section{RESUMO}

O artigo analisa a eficiência das decisões proferidas no âmbito do OSC a partir do US Farm Bill de 2014 e do DS522 (2016), normativas que tratam de novos subsídios fornecidos respectivamente pelos Estados Unidos da América ao setor do algodão e pelo Canadá à indústria aeronáutica com potencial de produção de efeitos sobre os países concorrentes, como aqueles decorrentes do DS267 e DS46, DS70 e DS222. Em que pese à existência de decisões já proferidas no âmbito do OSC em relação a esses dois países, foram adotados, no curto prazo, mecanismos para fornecer novos subsídios, em desrespeito aos acordos internacionais que questionam, via de consequência, a autoridade do OSC e da própria OMC. Para a elaboração deste estudo, foi utilizado o método hipotético-dedutivo e o ferramental da Análise Econômica do Direito, especialmente o conceito de eficiência. Inicia-se com a apresentação do conceito de eficiência, seguido de uma abordagem sobre o OSC, em especial, sobre o procedimento de tomada e implementação das decisões. Na sequência, foram analisados os DS267 e DS46, DS70 e DS222 para fundar as bases necessárias para introduzir o US Farm Bill de 2014 e o DS522 (2016) e, consequentemente, questionar a eficiência das decisões proferidas no âmbito do OSC.

Palavras-chave: Análise Econômica do Direito. Eficiência. Órgão de Solução de Controvérsias. Organização Mundial do Comércio. Subsídios Internacionais.

\section{INTRODUÇÃO}

Em fevereiro de 2017, o Brasil iniciou uma consulta perante o Órgão de Solução de Controvérsias da OMC (OSC) contra o Canadá para questionar os subsídios concedidos

* Doutoranda em Direito Econômico e Desenvolvimento na PUC/PR (Bolsista FA/CAPES). Mestra em Direito Econômico e Socioambiental pela PUC/PR (Bolsista CNPQ). Editora-Geral da Revista de Direito Empresarial. Advogada, Curitiba/PR, Brasil. E-mail: <lara@rochaefloriani.com.br>. https:/orcid.org/0000-0002-8112-0949

** Mestra em Direito Privado e Doutora em Direito das Relações Sociais pela UFPR. Professora Titular de Direito Societário da PUC PR. Professora Associada de Direito Empresarial da UFPR. Professora do Programa de Pós-Graduação em Direito da PUC PR e UFPR. E-mail: <marcia.ribeiro@pucpr.br>. https://orcid.org/0000-0001-7540-5406 
à indústria aeronáutica, especificamente à Bombardier, empresa canadense sediada em Montreal, Quebec.

O Canadá aceitou aderir à consulta, mas já adiantou, por intermédio de seus representantes de relações exteriores, que os subsídios concedidos não violam acordos internacionais.

A consulta (DS522) é relevante por remeter ao DS267, a respeito dos subsídios concedidos pelos Estados Unidos à agricultura do algodão, que, após mais de dez anos de duração, quando encerrado, foi seguido pelo lançamento da política agrícola Farm Bill de 2014, que criou mecanismos ainda mais gravosos do que aqueles que foram contestados na disputa, agora pela via de subsídios indiretos.

Esses casos conduzem à reflexão a respeito da eficiência das decisões tomadas no âmbito da OSC, em um contexto em que se têm dois exemplos de países de alto grau de desenvolvimento, a saber, Estados Unidos e Canadá. Após perderem disputas resolvidas no âmbito do OSC, esses países avançaram ao máximo durante a fase de execução prevista pelo Entendimento relativo às normas e aos procedimentos do OSC (ESC), chegando ao nível da retaliação ao criarem, no curto prazo, mecanismos para novamente burlar acordos internacionais.

A situação conduz a questionamentos sobre até que ponto o OSC é dotado do necessário enforcement para garantir o cumprimento de acordos internacionais regulados pela OMC. Significa também analisar se as decisões proferidas após a aprovação dos relatórios pelos Grupos Especiais ou pelo Órgão de Apelação podem ser, nesse contexto, consideradas eficientes, no sentido de vincular os vencidos e evitar a repetição do comportamento desviante.

Para responder aos questionamentos, foi utilizado o método hipotético-dedutivo.

$\mathrm{O}$ artigo se inicia pela proposta de identificação das falhas na implementação, no longo prazo, das decisões proferidas no âmbito do OSC, formulando-se a hipótese a que se pretende responder, vale dizer, se as decisões proferidas pelo OSC podem ser consideradas eficientes.

Na sequência, mediante processo de inferência dedutiva, busca-se testar a predição da ocorrência de fenômenos abrangidos pela hipótese.

O parâmetro utilizado para testar a hipótese levantada foi o conceito de eficiência, fornecido pelo ferramental da Análise Econômica do Direito. Desse modo, o artigo se inicia com a apresentação desse conceito e de sua aplicação na análise da eficiência das decisões do OSC.

Na sequência, analisa-se o modo de funcionamento do OSC, com ênfase no processo decisório e executório, fundando-se as bases necessárias para a análise dos DS46, DS70 e DS222, que se referem a disputas entre Brasil e Canadá, e DS267, entre Brasil e Estados Unidos da América. As disputas questionam os subsídios concedidos por um país a determinado setor da economia, considerados violadores de tratados internacionais.

A partir dos resultados abordados nestas disputas, o item subsequente trata da disputa DS522 (2016) entre Brasil e Canadá, em relação aos subsídios canadenses à indústria 
aeoronáltica e do Farm Bill, política norte-americana em favor do setor agrícola, que prevê a regra de pagamentos diretos aos produtores e introduz gerenciamento de risco, aprovada pelos EUA em fevereiro de 2014.

Objetiva-se com esta análise, evidenciar que tanto o DS522 (2016) como também o Farm Bill envolvem os mesmos estados partes das disputas DS46, DS70 e DS222, Brasil e Canadá, referente aos subsídios às indústrias aeronáuticas Embraer e Bombardier e DS267, Brasil e Estados Unidos da América, quanto aos subsídios de algodão e que, em tese, estas políticas teriam violado novamente acordos internacionais.

Ao final, serão tecidas considerações a respeito da eficiência das decisões proferidas no âmbito do OSC, considerando o Farm Bill de 2014 e o DS522 em curtos períodos de tempo, após os DS46, DS70 e DS222, relativos aos subsídios, à aeronáutica e aos DS267, que questionou subsídios ao setor de algodão.

\section{EFICIÊNCIA NA ANÁLISE ECONÔMICA DO DIREITO}

Ronald Coase, vencedor do Prêmio Nobel de Economia de 1991 pelas suas contribuições ao direito, à economia e às organizações, ao tratar do problema do custo social, afirma que, em uma sociedade na qual os recursos não são escassos, as escolhas feitas pelas partes não geram custos de transação (COASE, 2010).

Contudo, em uma realidade na qual há escassez de recursos, os indivíduos precisam fazer escolhas para satisfazer suas vontades ilimitadas e aumentar o seu bem-estar. Assim, cada escolha pressupõe um custo ou, como determina Ivo Teixeira Gico Jr., um trade-off ou um custo de oportunidade (GICO JUNIOR, 2011).

Ao escolher determinada opção, o indivíduo deixa de usufruir das consequências das demais escolhas, pois, segundo sua percepção (racionalidade limitada) (RIBEIRO, 2011), a primeira opção é aquela que, por apresentar custos de oportunidade inferiores aos das demais, seria apta a aumentar seu bem-estar. Vale dizer que a conduta dos indivíduos é racional maximizadora, uma vez que busca a promoção de seu bem-estar da forma menos custosa (ROCHA, 2015).

A eficiência está, portanto, diretamente relacionada à alocação de recursos com o menor custo possível, a fim de que o bem-estar seja maximizado, sem que se configurem desperdícios.

Posner (1983) afirma que a ferramenta de estudo utilizada pela economia é o comportamento dos indivíduos e a organização dos mercados e que esse ferramental se baseia na premissa de que as pessoas são racionais maximizadoras de suas satisfações e que, por isso, respondem a incentivos. Com os incentivos corretos, os recursos serão alocados de forma eficiente. Por outro lado, sem incentivos ou com incentivos desenhados de forma equivocada, a alocação tenderá a ser custosa, configurando-se o desperdício, em prejuízo da eficiência.

Nessa linha, as instituições existem para ordenar o modo como os indivíduos são afetados pelas consequências de seus atos. Quando fortes, têm o condão de reduzir incertezas, criando um ambiente favorável à realização de transações (ROCHA, 2015). 
Na lição de Douglass North, as instituições são restrições ao comportamento humano que garantem segurança e estabilidade, na medida em que disciplinam as oportunidades que os agentes têm ao adotar suas condutas (NORTH, 1990).

Quando as consequências forem vantajosas, haverá um incentivo para essa escolha. Em contrapartida, havendo consequências indesejadas, as instituições podem restringir o conjunto de possibilidades dos agentes durante o processo de escolha.

De acordo com Lorini (2016), as instituições são sistemas de regras constitutivas, que podem ser regras regulativas e constitutivas. As primeiras, segundo o autor, regulam uma atividade preexistente, e as constitutivas estabelecem uma atividade cuja existência é logicamente dependente das regras (LORINI, 2016).

Lorini (2016) parte da premissa de que as regras constitutivas criam a possibilidade de novas formas de comportamento. Em ensaio que investigou a forma por meio da qual uma atividade institucional é criada por meio de regras constitutivas, destacou que as regras podem criar possibilidades de novas formas de comportamento, mas não podem, por si só, criar uma nova prática. Em outros termos, as regras constitutivas certamente influenciam novos comportamentos. Contudo, não são uma condição necessária e suficiente de uma prática (LORINI, 2016).

Tecidas essas considerações, tem-se o Órgão de Solução de Controvérsias (OSC) da Organização Mundial do Comércio (OMC) como organização apta a moldar o comportamento dos Estados Membros da OMC, no que se refere ao cumprimento dos acordos internacionais e das decisões proferidas em seu âmbito de atuação.

Com decisões eficientes, sob o ponto de vista da AED, os Estados-Membros tenderão a cumprir os acordos internacionais que regem o comércio internacional, por estarem cientes de que eventual descumprimento implicará consequência desvantajosa e indesejada. Se, por outro lado, o descumprimento das decisões for interessante, seja sob o ponto de vista financeiro, político ou social, seja sob a inexistência de incentivos negativos adequados, o comportamento adotado tenderá a ser o do descumprimento e/ou desconsideração dos acordos internacionais ratificados.

Como consequência, a alocação dos recursos será ineficiente, pois exigirá tanto do Estado-Membro prejudicado como do próprio OSC e da OMC, condutas ativas, que, por sua vez, apresentam custos associados à finalidade última da execução da decisão proferida no âmbito do OSC, qual seja, o estabelecimento de um ambiente no âmbito do comércio internacional compatível com premissas de desenvolvimento econômico e social.

\section{3 ÓRGÃO DE SOLUÇÃO DE CONTROVÉRSIAS DA ORGANIZAÇÃO MUN- DIAL DO COMÉRCIO}

O Órgão de Solução de Controvérsias (OSC) é uma das organizações mais dinâmicas da OMC. A sua criação permitiu a definição do alcance dos acordos que compõem o acervo normativo da $\mathrm{OMC}$, contribuindo, desse modo, para conferir maior segurança e transparência 
ao funcionamento do sistema multilateral do comércio (LOPES, 2014).

O OSC é caracterizado por priorizar a negociação como forma de dirimir conflitos, em detrimento da aplicação de sanções aos Estados. A meta é sempre obter uma solução mutuamente satisfatória para as partes envolvidas. Sendo assim, há a possibilidade de as partes, em qualquer etapa do procedimento de solução de controvérsias, mesmo após a abertura de um Grupo Especial, solucionarem um conflito por meio de um acordo, de bons ofícios, conciliação, mediação e arbitragem (BRASIL, 2017c).

O OSC é regido pelo Entendimento Relativo às Normas e Procedimentos sobre Solução de Controvérsias (ESC) que define seu âmbito e aplicação, administração e procedimentos para a solução de controvérsias.

O primeiro procedimento previsto pelo OSC é o de consultas, que decorre da busca por uma solução mutuamente satisfatória para as partes, pela via diplomática. É uma fase obrigatória, que precede ao estabelecimento do Grupo Especial (art. $4^{\circ}$ do ESC) (BRASIL, 2017c). O membro/parte deve conceder oportunidade para a consulta com relação às medidas adotadas que afetem o funcionamento de qualquer acordo abrangido. As consultas não prejudicam o direito de qualquer membro em qualquer procedimento posterior (KOURY, 2006).

Se um membro não participante ou não envolvido diretamente com a questão demonstrar interesse comercial substancial nas consultas, pode ser integrado a elas como terceiro interessado (BRASIL, 2017c).

O requerimento de abertura de um Grupo Especial poderá ser feito nos casos de falta de resposta para a solicitação de consultas no prazo de dez dias, de não efetivação das consultas dentro de prazo não superior a trinta dias, ou de inviabilidade de se encontrar uma solução efetiva para a controvérsia por meio das consultas realizadas (BRASIL, 2017c).

Assim, não havendo êxito na fase de consultas, pede-se a abertura dos Grupos Especiais, que se dá a pedido da parte interessada no caso. Esse pedido deve ser apresentado em uma reunião do OSC e é fundamental que seja claro e identifique as medidas da controvérsia, nos mesmos moldes em que se deu o procedimento da consulta (BRASIL, 2017c).

A apresentação do relatório final dos Grupos Especiais não deve exceder seis meses da data de sua composição. Em casos urgentes, o prazo pode ser reduzido para três meses, por exemplo, para as situações que tratem de bens perecíveis (BRASIL, 2017c). Essa celeridade contribui para que seja conferida credibilidade ao OSC.

No relatório final, são apresentadas as considerações e as conclusões finais dos Grupos Especiais, e é sobre esse instrumento que o OSC emitirá recomendações e proferirá suas decisões. O relatório é redigido sem a presença das partes e será divulgado aos membros e às partes envolvidas, que terão sessenta dias para examiná-lo. Decorrido esse prazo, ocorre a reunião do OSC que irá aprovar, ou não, o relatório. Para essa decisão, aplica-se a regra do consenso negativo (KOURY, 2006), ou seja, encerrada a fase de consultas sem que tenha sido possível encontrar uma solução satisfatória para o caso, a constituição do Grupo 
Especial só poderá ser bloqueada se houver consenso de todos os membros, incluindo o demandante, o que, na prática, resultou em um sistema de jurisdição quase compulsória (BRASIL, 2017b).

O relatório final do Grupo Especial será considerado definitivo apenas se não houver apelação ao Órgão de Apelação. Esse órgão pode confirmar, modificar ou revogar as conclusões e as decisões jurídicas do Grupo Especial, respeitada a delimitação quanto à matéria em discussão (BRASIL, 2017c).

Assim como no Grupo Especial, o relatório do Órgão de Apelação deve ser apresentado em uma reunião do OSC no prazo de trinta dias contados de sua distribuição.

Observa-se que, na hipótese de interposição de apelação, o prazo total para a solução de uma controvérsia não pode exceder a doze meses.

As recomendações e as decisões do OSC devem ser cumpridas pelos países membros. Esse é um aspecto essencial para conferir credibilidade ao órgão, permitindo aos Estados confiança em sua autoridade (KOURY, 2006).

Após a aprovação do relatório final ou a apreciação da apelação, inicia-se o procedimento para aplicação das recomendações e das decisões do OSC. Nessa fase, o membro sobre o qual recaem as recomendações e as decisões deve informar suas intenções para a adoção das medidas pertinentes. Cabe ao OSC fiscalizar a adoção dessas medidas. $\mathrm{Na}$ hipótese de inadimplemento, o ESC prevê a possibilidade de compensação e de suspensão de concessões. São medidas temporárias, que somente devem ser aplicadas em última instância, valendo destacar que o objetivo do OSC não é punitivo, mas sim de resolução via acordos negociados.

A compensação deve ser negociada pelo membro que não cumpriu as recomendações no prazo indicado. Depende de solicitação do prejudicado, ela deve ser realizada antes de expirado o prazo estabelecido para o cumprimento e diz respeito a uma concessão tarifária e/ou compensação monetária pelos prejuízos sofridos (BRASIL, 2017c).

A suspensão de concessões, por sua vez, pode ser solicitada dentro dos vinte dias seguidos à data da expiração do prazo razoável, se não houver acordo quanto à compensação (BRASIL, 2017c). Em atenção ao princípio da proporcionalidade, o grau da suspensão de concessões ou outras obrigações deve ser equivalente ao grau de anulação ou prejuízo pela parte prejudicada na controvérsia (KOURY, 2006).

Assim, em um primeiro momento, busca-se a adoção pelo Estado-Membro das recomendações determinadas pelo OSC. Somente no caso de não serem adotadas as recomendações, permite-se que se negocie uma compensação. Apenas na hipótese de inexistência ou de insuficiência dessas últimas, surge a possibilidade de supressão de concessões ou outras obrigações (KOURY, 2006).

Inez Lopes destaca que, desde os primeiros casos submetidos à apreciação do OSC, sua atuação foi marcada por um viés institucional, a fim de se evitarem tensões e guerras. As retaliações são pouco aplicadas, em torno de 5\% (cinco) por cento dos casos julgados (LOPES, 2014). 
Em que pese aos importantes instrumentos autorizados para as negociações comerciais, cabe indagar até que ponto as retaliações são eficientes, principalmente considerando a impotência dos países menos desenvolvimentos ou em desenvolvimento para aplicar sanções aos países desenvolvidos (LOPES, 2014).

\section{DS46, DS70 E DS222 (BRASIL E CANADÁ) E DS267 (BRASIL E ESTADOS UNIDOS DA AMÉRICA)}

Os DS46, DS70, DS222 e DS267 representam disputas em que o Brasil participou e que se encerraram com a autorização para retaliações ao Estado-Membro vencido.

\subsection{DS 46 - CANADÁ X BRASIL}

Em 19 de junho de 1996, o Canadá iniciou um pedido de consultas ao Brasil, com fundamento no art. $4^{\circ}$ do Supply Chain Management (SCM Agreement), que prevê procedimentos especiais para subsídios de exportações, sob o argumento de que os subsídios fornecidos pelo Brasil, por meio do Programa de Financiamento às Exportações (PROEX), Lei n. 8.187/91), ${ }^{1}$ à Embraer apresentavam inconsistências com os artigos $3^{\circ}, 27.4$ e 27.5 do Acordo SCM (WORLD TRADE ORGANIZATION, 2017a).

No mês de setembro do mesmo ano, o Canadá requereu a instalação de um painel, alegando violações do Acordo SCM e também do GATT 1994. O OSC apreciou esse requerimento em sua reunião ocorrida em 27 de setembro de 1996. Em virtude da objeção do Brasil em compor o painel, o Canadá concordou em modificar o pedido, limitando o escopo para o Acordo SCM. O pedido de modificação foi submetido pelo Canadá à reunião do OSC em que seria analisado em 3 de outubro de 1996 (WORLD TRADE ORGANIZATION, 2017a).

Em 10 de julho de 1998, o Canadá solicitou novamente a instalação do painel, o que foi feito em 23 de julho de 1998 (DS46). A Comunidade Europeia e os Estados Unidos da América participaram da disputa como terceiros interessados (WORLD TRADE ORGANIZATION, 2017a).

Em 14 de abril de 1999, o relatório final dos Grupos Especiais circulou entre os membros, e, ao final, o painel considerou que as medidas adotadas pelo Brasil eram inconsistentes em relação aos artigos 3.1 (a) e 27.4 do Acordo SCM (WORLD TRADE ORGANIZATION, 2017a).

Em 3 de maio de 1999, o Brasil notificou sua intenção de apelar a respeito de certos pontos e interpretações legais desenvolvidas no painel. Em 2 de agosto, o relatório do Órgão de Apelação foi distribuído aos membros, ocasião em que foram confirmadas todas as conclusões do painel, exceto a interpretação da cláusula "vantagem importante" no item (k) da Lista Ilustrativa de Subsídios de Exportação no Anexo I do Acordo SMC (WORLD TRADE ORGANIZATION, 2017a).

Em 20 de agosto de 1999, o OSC aprovou o relatório do Órgão de Apelação e o relatório do painel, e, na sequência, em 19 de novembro de 1999, o Brasil revogou as medidas 
desaconselhadas no prazo de noventa dias e implementou as recomendações de decisões do OSC (WORLD TRADE ORGANIZATION, 2017a).

Em 23 de novembro de 1999, o Canadá questionou a implementação da decisão do OSC pelo Brasil. O Canadá e o Brasil também notificaram o OSC a respeito da possibilidade de um acordo relativo aos procedimentos a serem aplicados na hipótese de descumprimento, conforme preveem os artigos 21 e 22 do ESC. O painel inicial foi composto, e seu relatório foi distribuído aos membros em 9 de maio de 2000, tendo sido constatado que o Brasil não havia cumprido, como deveria, as recomendações do OSC (WORLD TRADE ORGANIZATION, 2017a).

Em 22 de maio de 2000, o Brasil notificou sua intenção de recorrer da decisão, que foi confirmada pelo Órgão de Apelação. O relatório foi adotado pelo OSC em 4 de agosto de 2000 (WORLD TRADE ORGANIZATION, 2017a).

Na reunião do OSC de 12 de dezembro de 2000, o Brasil informou que havia adotado as medidas cabíveis para implementação da decisão do OSC, alegou que o PROEX estava compatível com o Acordo SMC. O Canadá, em contrapartida, considerou que o Brasil continuava a violar suas obrigações, o que lhe rendeu autorização para adotar contramedidas contra o Brasil (WORLD TRADE ORGANIZATION, 2017a).

\subsection{DS70 E DS222 - BRASIL X CANADÁ}

No ano seguinte ao pedido de consultas formulado pelo Canadá em relação ao Brasil, este iniciou, em 10 de março de 1997, um pedido de consultas contra o Canadá com o fim de questionar subsídios garantidos pelo Governo do Canadá ou suas províncias para financiar a exportação de aeronaves civis. O pedido foi formulado nos termos do artigo $4^{\circ}$ do Acordo SMC, sob o argumento de que tais medidas contrariavam o artigo $3^{\circ}$ do mesmo acordo (WORLD TRADE ORGANIZATION, 2017b).

Em julho de 1998, o Brasil requereu o estabelecimento de um painel (DS70), e os Estados Unidos da América e a Comunidade Europeia participaram como partes interessadas (WORLD TRADE ORGANIZATION, 2017b).

O relatório do painel circulou entre os membros do Órgão Especial e, ao final, concluiu que certas medidas adotadas pelo Canadá eram inconsistentes em relação aos artigos 3.1 (a) e 3.2 do Acordo SMC. O Canadá recorreu da decisão, mas o Órgão de Apelação manteve o relatório do Grupo Especial (WORLD TRADE ORGANIZATION, 2017b).

Em 19 de novembro de 1999, o Canadá informou que iria cumprir as recomendações do OSC. Em 23 de novembro do mesmo ano, o Brasil requereu a aplicação dos arts. $21 \mathrm{e}$ 22 do ESC, a fim de implementar as recomendações do OSC (WORLD TRADE ORGANIZATION, 2017b).

O Canadá questionou a aplicação das contramedidas, afirmando que havia dado início ao cumprimento das recomendações, o que foi reconhecido pelo OSC em 04 de agosto de 2000 (WORLD TRADE ORGANIZATION, 2017b). 
Em 22 de janeiro de 2001, o Brasil solicitou consulta ao Canadá sobre os subsídios concedidos ao setor de aeronaves regionais do Canadá. Segundo o Brasil, as concessões violavam o artigo $3^{\circ}$ do Acordo SMC (WORLD TRADE ORGANIZATION, 2017c).

Na sequência, foi instalado um painel, em 12 de março de 2001, que teve Austrália, Comunidade Europeia, Índia e Estados Unidos da América como partes interessadas. Em 11 de maio de 2001, o painel foi composto (DS222) (WORLD TRADE ORGANIZATION, 2017c).

O painel concluiu, em 19 de fevereiro de 2002, que apenas uma das queixas levantadas pelo Brasil violava o artigo 3.1 (a) do Acordo SCM e determinou que o Canadá retirasse o subsídio no prazo de noventa dias (WORLD TRADE ORGANIZATION, 2017c).

Em 8 de março do mesmo ano, o Canadá afirmou que estava considerando opções de como melhor implementar as recomendações do OSC. Em 23 de maio de 2002, sob o argumento de que o Canadá havia falhado em implementar as decisões, o Brasil requereu autorização do OSC para aplicar retaliações, nos termos do artigo 22.2 do ESC (WORLD TRADE ORGANIZATION, 2017c).

O Canadá questionou o direito do Brasil de aplicar contramedidas, mas, ao final, foi garantido o direito do Brasil de suspender concessões sobre trocas no importe de US\$ 247.797.000,00 (duzentos e quarenta e sete milhões e setecentos e noventa e sete mil dólares). Na sequência, o Brasil requereu autorização para suspender concessões sobre outras obrigações, o que foi autorizado pelo OSC, em 18 de março de 2003 (WORLD TRADE ORGANIZATION, 2017c).

Nessa disputa, o Brasil obteve uma autorização semelhante àquela que o Canadá havia obtido no DS46, o que levou ambos os países à mesa de negociação. $\mathrm{O}$ acordo entre as partes resultou, em 2007, na revisão das regras de crédito de exportações de aeronaves no âmbito da Organização para Cooperação e Desenvolvimento Econômico (OCDE) (BRASIL, 2017a).

\subsection{DS267 - BRASIL X EUA}

O DS267 é um dos contenciosos mais longos da história do OSC, em que o Brasil questionou os subsídios concedidos pelos EUA à produção doméstica e à exportação de algodão no período de 1999-2002.

No ano de 2002, o Ministro Pratini de Moraes e a ABRAPA (Associação Brasileira de Produtores de Algodão) questionaram os subsídios internacionais dos EUA em relação à produção doméstica e à exportação de algodão (OLIVEIRA, 2010).

Sem êxito na fase de consultas, em 18 de março de 2003, foi estabelecido o painel que apresentou relatório final em 08 de setembro de 2003, o qual concluiu que os subsídios garantidos pelos EUA contrariavam acordos internacionais (WORLD TRADE ORGANIZATION, 2017d).

Em 18 de outubro de 2004, os EUA recorreram ao Órgão de Apelação que reformou parcialmente o relatório do Grupo Especial e concluiu que os subsídios eram proibidos e deveriam ser retirados (WORLD TRADE ORGANIZATION, 2017d). 
O prazo para implementar as decisões do OSC transcorreu sem que os EUA retirassem os subsídios considerados violadores dos acordos internacionais, e o Brasil requereu, em 18 de agosto de 2006, a aplicação de contramedidas (WORLD TRADE ORGANIZATION, 2017d).

Após uma série de requerimentos de implementação, sem êxito, o Brasil finalmente obteve a autorização do OSC para suspender concessões incidentes sobre bens e serviços de propriedade intelectual (WORLD TRADE ORGANIZATION, 2017d).

A suspensão afetaria as exportações de produtos norte-americanos para o Brasil, aumentando o Imposto sobre Importação além do limite acordado no âmbito da OMC, sem prejudicar o consumidor brasileiro. Afetaria, igualmente, o recebimento de direitos dos americanos sobre patentes, farmacêuticos, softwares, músicas e filmes (OLIVEIRA, 2010).

Quando as retaliações estavam prestes a serem colocadas em prática, os EUA apresentaram uma proposta de acordo que foi aceita pelo Brasil. A proposta envolvia medidas compensatórias e, dentre elas, a criação de um fundo para o setor de algodão com repasses anuais de US\$147,3 milhões durante a vigência do memorando, a serem aplicados em Assistência Técnica e Capacitação (OLIVEIRA, 2010).

\section{US FARM BILL (2014) E DS522}

Após o encerramento, em 2010, dos contenciosos acima analisados e logo após a suspensão do cumprimento de uma das obrigações constantes do Memorando de Entendimentos firmado entre Brasil e EUA (GOVERNO..., 2014), os EUA aprovaram, em fevereiro de 2014, o Farm Bill, que, em análise preliminar, teria o condão de produzir efeitos ainda mais prejudiciais aos produtores brasileiros do que o sistema de subsídios anterior (GOMES; WINTER; HASTREITER, 2017).

Essa nova política norte-americana em favor do setor agrícola tem previsão de cinco anos de duração. O Farm Bill prevê a regra de pagamentos diretos aos produtores e introduz gerenciamento de risco, ferramentas que oferecem proteção quando os agricultores sofrem perdas significativas. Além disso, reduz o limite de pagamentos, força o seguro agrícola, por intermédio de uma parceria público-privada, garantindo que os agricultores invistam na sua própria gestão de riscos. Também traz ferramentas de apoio a pequenas empresas, a agricultores e a fazendeiros com programas de treinamento e acesso ao crédito (GOMES; WINTER; HASTREITER, 2017).

Segundo Eduardo Gomes, Luis Alexandre Carta Winter e Michele Hastreiter, o Farm Bill, ao reduzir subsídios diretos, adotou medidas indiretas que, de acordo com a ABRAPA, podem trazer efeitos futuros distorcidos nas trocas internacionais. Entre elas, os autores citam o seguro agrícola, em que os prêmios são até $80 \%$ subsidiados pelo governo e garantem 90\% dos ganhos esperados pelos produtores (GOMES; WINTER; HASTREITER, 2017), realidade muito diferente daquela vivenciada em outros países, inclusive no Brasil.

Em virtude dessas previsões, o Brasil ameaçou reabrir o caso do algodão, uma vez que um estudo da ABRAPA demonstrou a possibilidade de o setor de algodão sofrer uma 
redução de rendimentos estimada em US\$340 milhões, em virtude da nova política agrícola norte-americana. Para prevenir uma nova disputa, o governo dos EUA concordou em pagar US $\$ 300$ milhões a título de compensação aos produtores brasileiros, em troca da promessa de que o Brasil não iria reabrir a disputa em 2018 (GOMES; WINTER; HASTREITER, 2017).

De todo modo, entende-se que o Farm Bill pode e deve ser questionado perante o OSC, na medida em que compromete a eficácia de regras significativas estabelecidas pela OMC e produz impactos sobre setores importantes para a economia brasileira (GOMES; WINTER; HASTREITER, 2017).

Vale dizer que, após uma disputa que se desenvolveu e teve desdobramentos por mais de dez anos, o vencido, no caso, os EUA implementaram uma nota política ainda mais prejudicial do que aquela questionada anteriormente, mas, agora, valendo-se de mecanismos indiretos de fornecimento de subsídios.

Em conduta semelhante, o Canadá, igualmente após três disputas que envolveram as mesmas partes e que demandaram também mais de dez anos, lançou, em 2016, novos subsídios ao setor da aeronáutica que, ao menos em tese, violam o artigo 3.1 (a) do Acordo SCM, o mesmo que fundou o DS46, DS70 e DS222.

Segundo nota emitida pelo Ministério das Relações Exteriores, o governo da província do Quebec injetou US $\$ 2,5$ bilhões na Bombardier em 2016, havendo indícios de que um aporte igualmente significativo seria feito em breve para viabilizar a nova linha de aviões C-Series e sua colocação no mercado a preços artificialmente reduzidos (HAYNES, 2016).

O Brasil sustenta que esse apoio financeiro tem afetado as condições de competitividade no mercado, permitindo à Bombardier fornecer aviões a um preço abaixo do custo de mercado (CAMEX, 2016).

Em virtude dessas concessões, o Brasil iniciou, em 8 de fevereiro de 2017, um pedido de consultas perante o OSC, a respeito das medidas adotadas pelo Canadá referentes às compras e às vendas de aeronaves comerciais. $\mathrm{O}$ Brasil alegou que as medidas aparentam ser inconsistentes com os artigos 3.1(a), 3.1 (b), 3.2, 5(c), 6.3(b), 6.3(c), 6.4 e 6.5, todos do Acordo SCM (WORLD TRADE ORGANIZATION, 2017e).

Em 23 de fevereiro de 2017, o Japão requereu participação como terceiro interessado e, no dia seguinte, a União Europeia e os Estados Unidos também, o que foi aceito pelo Canadá (WORLD TRADE ORGANIZATION, 2017e).

A fase de consultas ainda não foi encerrada, mas o Canadá já adiantou que os subsídios não violam qualquer obrigação internacional.

\section{CONCLUSÃO}

O OSC tem desempenhado, desde a sua criação, papel fundamental na economia mundial, na medida em que tem buscado atuar efetivamente na solução de controvérsias entre Estados-Membros da OMC. 
Tem-se mostrado acessível aos Estados-Membros, inclusive, àqueles em estágio de desenvolvimento, e garantido respostas em tempo hábil às consultas solicitadas e à instalação dos painéis, na hipótese de não ter havido êxito na fase inicial.

O problema recai, contudo, na fase de implementação das decisões finais, o que afeta sobremaneira a eficiência decisória do OSC. Verificou-se, pela análise dos casos abordados neste artigo, que mesmo as autorizações de retaliações em valores altíssimos, não foram suficientes para inibir comportamentos futuros violadores de acordos internacionais.

Os EUA e o Canadá, poucos anos após o encerramento de duas das maiores disputas levadas a efeito perante o OSC, implementaram novos subsídios, contrariando acordos internacionais e evidenciando que as contramedidas autorizadas não foram suficientes para prevenir o comportamento indesejado que havia sido objeto de punição nas disputas.

As condutas adotadas por esses países, mediante o lançamento do Farm Bill e a implementação dos subsídios que deram origem ao DS522, colocam em xeque a eficiência das decisões do OSC, que não foram aptas a alocar, com o menor custo, os recursos, maximizando, como se desejava e esperava, o bem-estar dos Estados-Membros que o acionaram.

A implementação das decisões exigiu reiterados pedidos de instalação de painéis e de autorização de contramedidas, o que se traduz em custos de funcionamento do órgão e de acesso ao Estado solicitante e, ainda assim, não cumpriram com o seu papel de funcionar como incentivo adequado a pôr fim a qualquer tentativa de violação de acordos internacionais.

Vale dizer que, a partir da análise da atuação do OSC, mostrou-se mais vantajosa aos países demandantes a conduta que viola os acordos internacionais. Os rendimentos decorrentes dos subsídios proibidos são superiores à eventual suspensão de concessão que, no fim, se desdobra em um acordo compensatório ou em um memorando de entendimentos.

Além disso, há de se destacar que os efeitos indesejados da falta de eficiência das decisões do OSC alcançam também as partes interessadas na disputa. A possibilidade de participação de terceiros nas disputas, na forma prevista no ESC, tem como objetivo prevenir novos conflitos, uma vez que o resultado das consultas e as decisões finais do OSC podem vincular comportamentos futuros.

Assim, se, ao final da disputa, o comportamento desviante se torna mais interessante, os terceiros interessados podem ser negativamente influenciados a adotar comportamentos oportunistas, pois estão cientes de que a eventual adoção de contramedidas não atinge de forma significativa a percepção de lucro que decorre da concessão de subsídios proibidos pelos acordos internacionais, como verificado nos exemplos abordados neste artigo.

A implementação das decisões do OSC pode maximizar o bem-estar do país violador, desvirtuando o objeto de atuação do próprio órgão. Dada sua importância no cenário do comércio internacional, é preciso, portanto, repensar medidas de enforcement, a fim de garantir eficiência plena às decisões do OSC. 


\title{
US FARM BILL (2014) AND DS522 LITIGATION X EFFICIENCY OF DSB DECISIONS
}

\begin{abstract}
This article examines the efficiency of the DSB rulings from the US Farm Bill of 2014 and DS522 (2016) since they are new subsidies provided by the United States of America to the cotton sector and by Canada to aeronautics industry, with potential effects to affect competing countries, as those subject to DS267 and DS46, DS70 and DS222. In other words, despite the decisions already made within the scope of the DSB in relation to these two countries, mechanisms were found in the short term to provide new subsidies, in disregard of international agreements questioning as a consequence the authority of the DSB and of the WTO itself. For the elaboration of this study, we adopted the hypothetical-deductive method and the tool of the Economic Analysis of Law, especially the concept of efficiency. This paper starts with the presentation of the concept of efficiency, followed by the DSB approach and, in particular, the procedure for making and implementing decisions. Subsequently, DS267 and DS46, DS70 and DS222 were analyzed to lay the foundation for the introduction of the 2014 US Farm Bill and DS522 (2016) and, consequently, to investigate the efficiency of decisions made within the scope of the DSB.
\end{abstract}

Keywords: Economic Analysis of Law. Efficiency. Dispute Settlement Body. World Trade Organization. International Subsidies.

US FARM BILL (2014) Y DS522 (2016) X EFICIENCIA DE LAS DECISIONES DEL OSD

\section{RESUMEN}

Este artículo analiza la eficiencia de las decisiones dictadas en el OSD a partir del US Farm Bill de 2014 y del DS522 (2016), ya que introducen nuevos subsidios proporcionados por los Estados Unidos de América al sector del algodón y por Canadá a la industria aeronáutica, con potencial de producción de efectos para afectar a los países competidores, como los derivados del DS267 y DS46, DS70 y DS222. Por medio de los cuales, pese a las decisiones ya pronunciadas en el ámbito del OSD en relación a estos dos países, se han encontrado, en el corto plazo, mecanismos para proporcionar nuevos subsidios, en incumplimiento a los acuerdos internacionales y cuestionando, por consiguiente, la autoridad del OSD y de la propia OMC. Para la elaboración de este estudio se utilizó el método hipotético-deductivo y el instrumental de Análisis Económico del Derecho, especialmente el concepto de eficiencia. El artículo se inicia con la presentación del concepto de eficiencia, seguido del enfoque del OSD y, en particular, del procedimiento de toma y ejecución de las decisiones. En consecuencia, se analizaron los DS267 y DS46, DS70 y DS222 para fundamentar las bases necesarias para introducir el US Farm Bill de 
2014 y el DS522 (2016) y, por consiguiente, cuestionar la eficiencia de las decisiones dictadas en el ámbito del OSD.

Palabras clave: Análisis Económico del Derecho. Eficiencia. Órgano de Soluciones de Diferencias. Organización Mundial del Comercio. Subsidios Internacionales.

1 O programa representava um mecanismo de financiamento às exportações mediante a equalização das taxas de juros e financiamento direto.

\section{REFERÊNCIAS}

BRASIL. Ministério das Relações Exteriores. O Sistema de Solução de Controvérsias da OMC. Disponível em <http://www.itamaraty.gov.br/pt-BR/politica-externa/diplomacia-economica-comercial-e-financeira/15581-o-sistema-de-solucao-de-controversias-da-omc >. Acesso em: 15 jun. 2017a.

. Funcionamento do Sistema de Solução de Controvérsias da OMC. Disponível em: <http://www.itamaraty.gov.br/pt-BR/sem-categoria/14814-funcionamento-do-sistema-de-solucoes-de-controversias-da-omc $>$. Acesso em: 6 nov. $2017 \mathrm{~b}$.

. Entendimento Relativo às normas e procedimentos sobre solução de controvérsias. Art. 5(3) do ESC. Disponível em: < https://sistemas.mre.gov.br/kitweb/datafiles/ IRBr/ptbr/file/CAD/LXII\%20CAD/Direito/OMC\%20ANEXO\%202\%20Entendimento\%20relativo\%20as\%20normas\%20e\%20procedimentos\%20sobre\%20solucao\%20de $\% 20$ controversias.pdf. $>$. Acesso em: 20 jun. 2017c.

CAMEX autoriza abertura de processo contra o Canadá na OMC por subsídio. 2016. Disponível em: <http://www.em.com.br/app/noticia/economia/2016/12/19/internas_economia,833740/camex-autoriza-abertura-de-processo-contra-o-canada-na-omc-por-subsidi. shtml>. Acesso em: 20 jun. 2017.

COASE, Ronald. H. O problema do custo social. In: SALAMA, Bruno Meyerhof (Org.). Direito e Economia: textos escolhidos. Tradução Francisco Kummel F. Alves e Renato Vieira Caovilha. São Paulo: Saraiva, 2010.

GICO JUNIOR, Ivo Teixeira. Introdução à Análise Econômica do Direito. In: RIBEIRO, Marcia Carla Pereira; KLEIN, Vinicius (Coords.). O que é análise econômica do direito: uma introdução. Belo Horizonte: Fórum, 2011.

GOMES, Eduardo Biacchi; WINTER, Luis Alexandre Carta; HASTREITER, Michele Alessandra. Brazilian Interests and the United States' Farm Bill: The Ills of Protectionism. Revista de Direito Empresarial - RDEmp, Belo Horizonte, v. 14, n. 1, p. 117-136, jan./ abr. 2017. 
GOVERNO decide não retaliar EUA pelo descumprimento do contencioso do algodão. 2014. Disponível em: <http://www.canalrural.com.br/noticias/agricultura/governo-decide-nao-retaliar-eua-pelo-descumprimento-contencioso-algodao-24354 >. Acesso em: 20 jun. 2017.

HAYNES, Brad. Brazil to challenge Canada at WTO over Bombardier funding. 2016. Disponível em: <http://www.reuters.com/article/us-brazil-canada-wto-idUSKBN1481FA>. Acesso em: 20 jun. 2017.

KOURY, Luiz Guilherme Costa. Aspectos procedimentais do órgão de solução de controvérsias da OMC. Revista do CAAP., Minas Gerais, n. 1, p. 179-202, 2006.

LOPES, Inez. Órgão de solução de controvérsias da OMC: acesso aos países em desenvolvimento? Revista de Direito da Universidade de Brasília, v. 1, n. 2, p. 33-65, jul./dez. 2014. LORINI, Giuseppe. Regras Constitutivas Podem Criar uma Prática? Revista Opinião Jurídica, Fortaleza, v. 14, n. 18, p. 305-315, jan./jun. 2016.

NORTH, Douglass C. Institutions, Institutional Change and Economic Performance. New York: Cambridge University Press, 1990.

OLIVEIRA, Ivan Tiago Machado. A atuação do Brasil no sistema de solução de controvérsias da OMC: o caso do contencioso do algodão contra os EUA. Boletim de Economia e Política Internacional, Brasília, n. 2, p. 17-27, abr. 2010.

POSNER, Richard A. The Economics of Justice. Cambridge: Harvard University Press, 1983. RIBEIRO, Marcia Carla Pereira. Racionalidade Limitada. In: ; KLEIN, Vinicius (Coords.). O que é análise econômica do direito: uma introdução. Belo Horizonte: Fórum, 2011. ROCHA, Lara Bonemer Azevedo da. O desenvolvimento econômico pelo acesso à justiça. São Paulo: Boreal, 2015.

WORLD TRADE ORGANIZATION. DS46: Brazil: export financing programme for aircraft. Disponível em: < https://www.wto.org/english/tratop_e/dispu_e/cases_e/ds46_e. htm >. Acesso em: 20 jun. 2017a.

. DS70: Canada: measures affecting the export of civilian aircraft. Disponível em:

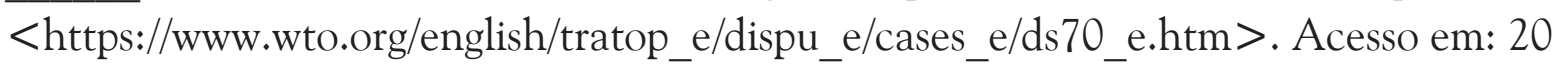
jun. 2017b.

. DS222: Canada: export credits and loan guarantees for regional aircraft. Disponível em: < https://www.wto.org/english/tratop_e/dispu_e/cases_e/ds222_e.htm>. Acesso em: 20 jun. 2017c.

. DS267: United States: subsidies on upland cotton. Disponível em: <https:// www.wto.org/english/tratop_e/dispu_e/cases_e/ds267_e.htm >. Acesso em: 20 jun. 2017d. . DS522: Canada: measures concerning trade in commercial aircraft. Disponível em: $<$ https://www.wto.org/english/tratop_e/dispu_e/cases_e/ds522_e.htm>. Acesso em: 10 jun. 2017e. 